\title{
Níveis de lisina digestível em rações, utilizando-se o conceito de proteína ideal, para suínos machos castrados de alto potencial genético, dos 30 aos $60 \mathrm{~kg}^{1}$
}

\section{Márvio Lobão Teixeira de Abreu$^{2}$, Juarez Lopes Donzele ${ }^{3}$, Rita Flávia Miranda de Oliveira ${ }^{3}$, Alexandre Luiz Siqueira de Oliveira ${ }^{4}$, Douglas Haese ${ }^{5}$, Adriana Aparecida Pereira ${ }^{6}$}

\author{
1 Parte da tese de Doutorado do primeiro autor. \\ 2 DZO/UFPI. \\ 3 DZO/UFV. \\ ${ }^{4}$ Fiscal Federal Agropecuário \\ ${ }^{5}$ Doutorando DZO/UFV. \\ ${ }^{6}$ Graduanda em Zootecnia/UFV. Bolsista IC-PIBIC/CNPq.
}

RESUMO - Objetivou-se determinar o efeito de níveis de lisina digestível, utilizando-se o conceito de proteína ideal, sobre o desempenho e as características de carcaça de 40 leitões machos castrados (peso inicial de 30,02 $\pm 1,38 \mathrm{~kg}$ e peso final $60,44 \pm$ $1,81 \mathrm{~kg}$ ) de alto potencial genético para deposição de carne magra. Os animais foram distribuídos em delineamento de blocos ao acaso, com quatro tratamentos, cinco repetições e dois animais por unidade experimental. Os tratamentos consistiram de uma ração basal $(18,08 \%$ de PB e $3.250 \mathrm{kcal}$ de EM/kg) suplementada com L-lisina HCL, resultando em rações com 0,80; 0,90; 1,00 e $1,10 \%$ de lisina digestível. As rações foram suplementadas com níveis crescentes de aminoácidos sintéticos, mantendo-se constantes as relações entre os níveis desses aminoácidos essenciais e os de lisina, com base na digestibilidade verdadeira. Não houve efeito dos tratamentos sobre o consumo de ração, o ganho de peso diário e a concentração de uréia no plasma dos animais. Observou-se comportamento linear da conversão alimentar, que melhorou, e do consumo de lisina digestível diário, que aumentou em função dos níveis de lisina digestível da ração. Os tratamentos não influenciaram as porcentagens de água, proteína e gordura e a deposição de gordura na carcaça dos animais. Os níveis de lisina digestível afetaram de forma linear crescente a deposição de proteína na carcaça. O nível de $1,10 \%$ de lisina digestível, correspondente a um consumo de lisina digestível de 21,94 g/dia (3,43 g de Lis/Mcal de EM) proporcionou os melhores resultados de desempenho e características de carcaça de suínos machos castrados de alto potencial genético dos 30 aos $60 \mathrm{~kg}$.

Palavras-chave: aminoácidos, carcaça, fase de crescimento, genótipo, uréia

\section{Dietary digestible lysine requirements, based on the ideal protein concept, for barrows with high genetic potential from 30 to $60 \mathrm{~kg}$}

\begin{abstract}
The effect of increasing dietary digestible lysine levels, based on the ideal protein concept, on performance and carcass characteristics of forty barrows with high genetic potential for lean gain averaging initial and final body weights of $30.02 \pm 1.38 \mathrm{~kg}$ and $60.44 \pm 1.81 \mathrm{~kg}$, respectively, was evaluated in this experiment. The animals were assigned to a randomized blocks design, with four treatments, five replicates and two animals per experimental unit. The treatments consisted of a basal diet (18.08\% of CP and 3,250 kcal of ME/kg) supplemented with increasing levels of HCL-L-lysine ( 0.80 , $0.90,1.00$, and $1.10 \%$ of digestible lysine). The diets were supplemented with constant synthetic amino acids:lysine ratios based on the true digestibility. No treatment effects on feed intake, daily weight gain and plasma urea concentration were observed. Feed:gain ratio and digestible lysine intake increased linearly as the dietary digestible lysine levels increased. No significant treatment effects on percentages of water, protein and fat and carcass fat deposition were observed. It was observed increasing linear effect of treatments on carcass protein deposition. The $1.10 \%$ digestible lysine level, that corresponds to a digestible lysine intake of $21.94 \mathrm{~g} / \mathrm{day}(3.43 \mathrm{~g}$ of Lys/Mcal of ME), resulted in the best performance and carcass characteristics of barrows with high genetic potential from 30 to $60 \mathrm{~kg}$.
\end{abstract}

Key Words: amino acids, carcass, genotype, growing phase, urea

\section{Introdução}

A cada ano, novos genótipos de suínos são introduzidos no mercado. Esses animais têm como uma das principais características econômicas a maior deposição de carne magra na carcaça, principal objetivo da criação de suínos para abate.

O nutriente mais importante para a deposição de carne magra na carcaça de suínos em crescimento é a lisina dietética, por sua constância na proteína corporal e sua 
destinação metabólica preferencial para a deposição de tecido magro (Kessler, 1998). Portanto, a exigência de lisina para suínos pode ser obtida a partir da taxa de deposição de proteína na carcaça dos animais.

A utilização do conceito de proteína ideal tem sido proposta para a formulação de rações em experimentos visando determinar as exigências de lisina para suínos. Segundo Yen et al. (1986), a mudança na concentração de lisina da ração deve ser acompanhada por alteração proporcional dos demais aminoácidos essenciais, pois o balanço ideal dos aminoácidos essenciais com a lisina evitaria possíveis variações nas respostas dos animais, o que ocasionaria erros na estimativa da exigência de lisina dos animais. Esse fato foi comprovado por Fontes (1999), em dois ensaios distintos com leitoas de mesmo potencial genético na fase de 30 a $60 \mathrm{~kg}$. O menor nível de lisina digestível recomendado por esse autor foi obtido com rações com níveis crescentes de lisina, sem ajustes nos níveis dos outros aminoácidos essenciais.

Além do genótipo, o peso corporal e o sexo são fatores que influenciam a taxa e a eficiência de deposição de proteína nos suínos e, conseqüentemente, a exigência de lisina dos animais.

Assim, este trabalho foi conduzido com o objetivo de determinar a exigência de lisina digestível, utilizando-se o conceito de proteína ideal, para suínos machos castrados, de alto potencial genético para deposição de carne magra na carcaça, dos 30 aos $60 \mathrm{~kg}$ de peso corporal.

\section{Material e Métodos}

O experimento foi conduzido no Setor de Suinocultura do Departamento de Zootecnia da Universidade Federal de Viçosa nos meses de abril e maio de 2002. Foram utilizados 40 suínos machos castrados de alto potencial genético para deposição de carne magra na carcaça, com peso inicial de $30,02 \pm 1,38 \mathrm{~kg}$, distribuídos em delineamento experimental de blocos ao acaso, com quatro tratamentos (níveis de lisina digestível), cinco repetições e dois animais por unidade experimental. Na distribuição dos animais em cada bloco, adotou-se como critério o peso inicial dos animais.

Os animais foram alojados em baias com comedouros semi-automáticos e bebedouros tipo chupeta, localizadas em galpão de alvenaria com piso de concreto e telhas de cerâmica.

As rações experimentais (Tabela 1) foram formuladas à base de milho e farelo de soja e suplementadas com minerais e vitaminas, de acordo com Rostagno et al. (2000), para atender às exigências dos animais, exceto de $\mathrm{PB}$ e lisina. Os tratamentos foram constituídos de uma ração basal sem suplementação de L-Lisina HCL e outras três rações suplementadas com L-Lisina HCL em substituição ao amido, resultando em rações com 0,80; 0,90; 1,00 e 1,10\% de lisina digestível.

Para cada nível de lisina avaliado, procurou-se manter a relação entre os aminoácidos essenciais (metionina + cistina, triptofano e valina) e a lisina, considerando os níveis preconizados por Rostagno et al. (2000) para suínos dos 30 aos $60 \mathrm{~kg}$. As rações e a água foram fornecidas à vontade.

As rações, as sobras e os desperdícios foram pesados semanalmente. Os animais, no entanto, foram pesados no início e ao final do período experimental, quando atingiram $60,44 \pm 1,81 \mathrm{~kg}$, para determinação do consumo de ração e de lisina, do ganho de peso e da conversão alimentar.

Ao final do experimento, um animal de cada unidade experimental com peso mais próximo da média da gaiola foi utilizado para avaliação da composição química e das deposições de proteína e gordura na carcaça. Após jejum de 24 horas, foram abatidos por sangramento, depilados com lança-chamas e faca e eviscerados. As carcaças inteiras, incluindo cabeça e pés, foram pesadas e a metade direita foi triturada em cutter comercial de $30 \mathrm{HP}$ e $1.775 \mathrm{rpm}$ por 20 minutos. O material foi homogeneizado e amostras foram retiradas para análise, conforme metodologia descrita por Donzele et al. (1992), e armazenadas a $-12^{\circ} \mathrm{C}$.

O outro animal da unidade experimental foi mantido em jejum alimentar durante 24 horas e, em seguida, recebeu ração à vontade por 1 hora. Posteriormente, os animais foram submetidos a jejum alimentar e hídrico por mais 5 horas para a coleta de sangue via punção do sinus orbital. O sangue foi centrifugado a 3.000 rpm durante 15 minutos para obtenção do plasma, que foi armazenado em congelador para posterior determinação da concentração de uréia plasmática (UP) por meio de processo enzimático utilizando-se kit comercial.

Um grupo adicional de quatro animais da mesma linhagem $(30,42 \pm 0,91 \mathrm{~kg})$ foi abatido para determinação da composição da carcaça no início do experimento. As amostras das carcaças foram pré-desengorduradas pelo método a quente em extrator tipo Soxhlet (4 horas) e pré-secas em estufa de ventilação forçada a $60^{\circ} \mathrm{C}$ por 72 horas. Seqüencialmente, foram trituradas em moinho de bola, acondicionadas em vidros e conservadas em geladeira para análises. A água e a gordura retiradas durante o preparo inicial das amostras foram consideradas nos cálculos de água, proteína e gordura da carcaça.

As análises dos ingredientes das rações e da água e da proteína e gordura das carcaças dos animais foram realizadas no Laboratório de Nutrição Animal do Departamento de 
Tabela 1 - Composição nutricional das rações experimentais

Table 1 - Nutritional composition of the experimental diets

\begin{tabular}{|c|c|c|c|c|}
\hline \multirow[t]{2}{*}{$\begin{array}{l}\text { Ingrediente }(\%) \\
\text { Ingredient }\end{array}$} & \multicolumn{4}{|c|}{$\begin{array}{c}\text { Nível de lisina digestível (\%) } \\
\text { Digestible lysine level }\end{array}$} \\
\hline & 0,80 & 0,90 & 1,00 & 1,10 \\
\hline Milho (Corn) & 66,740 & 66,740 & 66,740 & 66,740 \\
\hline Farelo de soja (Soybean meal) & 27,120 & 27,120 & 27,120 & 27,120 \\
\hline Amido (Starch) & 1,000 & 0,798 & 0,536 & 0,225 \\
\hline Óleo de soja (Soybean oil) & 1,710 & 1,710 & 1,710 & 1,710 \\
\hline Fosfato bicálcico (Dicalcium phosphate) & 1,380 & 1,380 & 1,380 & 1,380 \\
\hline Calcário (Limestone) & 0,810 & 0,810 & 0,810 & 0,810 \\
\hline L-lisina $\mathrm{H}-\mathrm{Cl}$ (HCL L-lysine) & - & 0,127 & 0,254 & 0,381 \\
\hline DL-metionina (DL-methionine) & - & 0,046 & 0,111 & 0,176 \\
\hline L-treonina (L-threonine) & - & 0,029 & 0,098 & 0,167 \\
\hline L-triptofano (L-thryptophan) & - & - & 0,001 & 0,020 \\
\hline L-valina (L-valine) & - & - & - & 0,031 \\
\hline Sal comum (Salt) & 0,330 & 0,330 & 0,330 & 0,330 \\
\hline Premix mineral $^{1}$ (Mineral mix) & 0,100 & 0,100 & 0,100 & 0,100 \\
\hline Premix vitamínico ${ }^{2}$ (Vitamin mix) & 0,300 & 0,300 & 0,300 & 0,300 \\
\hline Promotor crescimento ${ }^{3}$ (Growth promoter) & 0,500 & 0,500 & 0,500 & 0,500 \\
\hline B HT & 0,010 & 0,010 & 0,010 & 0,010 \\
\hline Total & 100,00 & 100,00 & 100,00 & 100,00 \\
\hline \multicolumn{5}{|l|}{$\begin{array}{l}\text { Composição nutricional calculada } 4 \\
\text { Calculated nutritional composition }\end{array}$} \\
\hline $\mathrm{ED}(D E)(\mathrm{kcal} / \mathrm{kg})$ & 3.430 & 3.430 & 3.430 & 3.430 \\
\hline $\mathrm{EM}(M E)(\mathrm{kcal} / \mathrm{kg})$ & 3.250 & 3.250 & 3.250 & 3.250 \\
\hline $\mathrm{PB}(C P)(\%)$ & 18,076 & 18,247 & 18,46 & 18,70 \\
\hline Lisina total $(\%)$ (Total lysine) & 0,921 & 1,022 & 1,124 & 1,225 \\
\hline Lisina digestível $(\%)^{5}$ (Digestible lysine) & 0,800 & 0,900 & 1,000 & 1,100 \\
\hline Metionina + cistina digestível $(\%)^{5}$ (Digestible methionine + cystine) & 0,531 & 0,576 & 0,640 & 0,704 \\
\hline Treonina digestível $(\%)^{5}$ (Digestible threonine) & 0,584 & 0,612 & 0,680 & 0,748 \\
\hline Triptofano digestível $(\%)^{5}$ (Digestible thryptophan) & 0,189 & 0,189 & 0,190 & 0,209 \\
\hline Valina digestível $(\%)^{5}$ (Digestible valine) & 0,729 & 0,729 & 0,729 & 0,759 \\
\hline $\mathrm{Ca}(\%)$ & 0,760 & 0,760 & 0,760 & 0,760 \\
\hline $\mathrm{P}$ disponível (\%) (Available $P$ ) & 0,360 & 0,360 & 0,360 & 0,360 \\
\hline $\mathrm{Na}(\%)$ & 0,170 & 0,170 & 0,170 & 0,170 \\
\hline
\end{tabular}

${ }^{1}$ Conteúdo/kg de produto (Content per kg of product): Ca - 98,80 g; Co - 185,0 mg; Cu - 15.750 mg; Fe - 26.250 mg; I 1.470 mg; Mn - 41.850 mg; Zn $77.999 \mathrm{mg}$.

2 Conteúdo/kg de produto (Content per kg of product): ácido fólico (folic acid) - 351,75 mg; ácido pantotênico (pantothenic acid) - 3.500 mg; antioxidante (BHT) $1.500 \mathrm{mg}$; biotina (biotine) - 18,90 mg; colina (choline) - 52,50 g; niacina (niacin) - 6.930 mg; vit. B6 - 630 mg; vit. B2 - $1.400 \mathrm{mg}$; Se - $131,25 \mathrm{mg}$; vit. B1 $350 \mathrm{mg}$; vit. A - $1.750 \mathrm{UI}$; vit. B12 - 8.750,70 mcg; vit. D3 - $700.000 \mathrm{UI}$; vit. E - $3.500 \mathrm{mg}$; vit. K3 - $700 \mathrm{mg}$.

3 Olaquindox, $11.000 \mathrm{mg} / \mathrm{kg}$.

${ }^{4}$ Composição calculada segundo Rostagno et al. (2000) (Calculated composition according to Rostagno et al., 2000).

${ }^{5}$ Valores estimados com base nos coeficientes de digestibilidade dos aminoácidos dos ingredientes, de acordo com Rostagno et al. (2000) (Estimated values based on the digestibility coefficients according to Rostagno et al., 2000).

Zootecnia da UFV, de acordo com as técnicas descritas por Silva (1990). As deposições de proteína e gordura nas carcaças foram calculadas comparando-se as composições das carcaças dos animais no início e ao final do período experimental.

As análises estatísticas das características de desempenho, das concentrações de uréia no plasma dos animais, da composição da carcaça e das deposições de proteína e gordura nas carcaças foram realizadas utilizando-se o Sistema de Análises Estatísticas e Genética -SAEG(UFV, 1997).

As estimativas de exigência de lisina digestível foram determinadas por meio de análises de regressão linear e quadrática.

\section{Resultados e Discussão}

Os resultados de desempenho, consumo diário de lisina digestível e concentração de uréia no plasma de suínos machos castrados dos 30 aos $60 \mathrm{~kg}$ recebendo diferentes níveis de lisina na ração encontram-se na Tabela 2 .

Não houve efeito $(\mathrm{P}>0,05)$ dos tratamentos sobre o consumo de ração, o que está de acordo com os resultados obtidos por Donzele et al. (1994), que avaliaram níveis de lisina total $(0,63$ a $1,03 \%)$ e não constataram efeito dos tratamentos sobre o CRD dos animais. Outros autores, como Friesen et al. (1994), Souza (1997) e Fontes et al. (2000), também não observaram efeito dos níveis de lisina da ração sobre o CRD dos animais. Por outro lado, Fontes 
Tabela 2 - Desempenho, consumo de lisina e nível de uréia no plasma de suínos machos castrados dos 30 aos 60 kg recebendo diferentes níveis de lisina na ração

Table 2 - Performance, digestible lysine intake and plasma urea level of barrows from 30 to $60 \mathrm{~kg}$ according to the dietary lysine levels

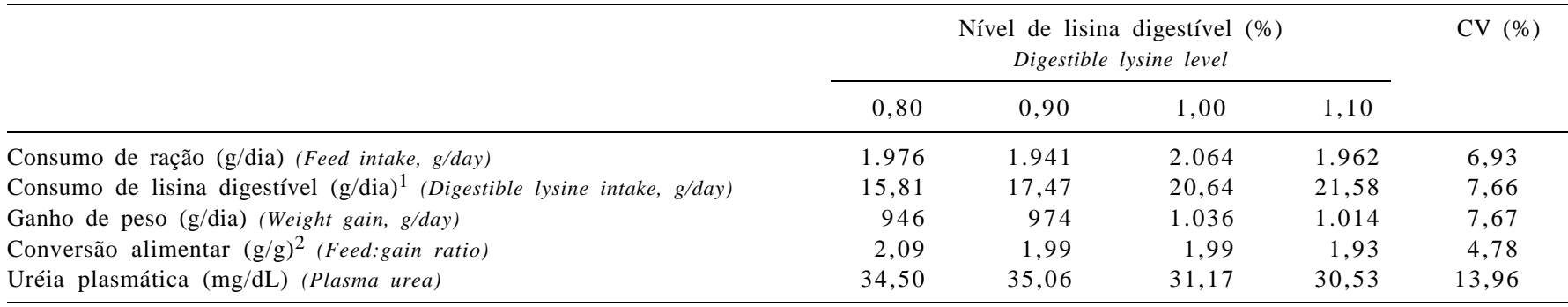

1,2 Efeito linear, $\mathrm{P}<0,01$ e $\mathrm{P}<0,05$, respectivamente.

1,2 Effect linear, $P<0.01$ and $P<0.05$, respectively.

et al. (2005), avaliando níveis de 0,80 a $1,20 \%$ de lisina total, constataram efeito linear dos tratamentos sobre o CRD de leitoas de alto potencial genético na fase de 30 a $60 \mathrm{~kg}$.

Segundo Edmonds \& Baker (1987), suínos podem tolerar consideráveis excessos de aminoácidos, principalmente lisina, sem apresentar variações significativas no consumo alimentar.

O desbalanço de aminoácidos tem como um dos sintomas característicos a diminuição do consumo voluntário de alimento pelos animais (D'Mello, 1993). Neste estudo, esse desbalanço pode ter sido evitado pela suplementação das rações com aminoácidos sintéticos, mantendo-se as relações entre os principais aminoácidos digestíveis e a lisina.

Corroborando os resultados obtidos por Fontes et al. (2000, 2005), observou-se aumento linear $(\mathrm{P}<0,01)$ do consumo de lisina digestível (CLD) com o acréscimo no nível de lisina das rações.

O aumento do CLD esteve diretamente relacionado aos aumentos de suas concentrações nas rações, visto que o consumo de ração dos animais não variou significativamente entre os tratamentos.

Os tratamentos não influenciaram $(\mathrm{P}>0,05)$ o ganho de peso diário (GPD) dos animais. Donzele et al. (1994), Souza (1997) e Fontes et al. (2000) também não observaram efeito dos níveis de lisina sobre o GPD de suínos de 30 a $60 \mathrm{~kg}$, enquanto Friesen et al. (1994) e Fontes et al. (2005), trabalhando com leitoas dos 34 aos 72 e dos 30 aos $60 \mathrm{~kg}$, respectivamente, constataram efeito dos níveis de lisina sobre o GPD de leitoas. Em outro estudo, Warnants et al. (2003) avaliaram níveis de lisina digestível para suínos machos castrados híbridos dos 30 aos 49 kg e notaram que o GPD dos animais foi influenciado de forma quadrática pelos tratamentos, elevando até o nível de 1,09\%.

A conversão alimentar $(\mathrm{CA})$ melhorou $(\mathrm{P}<0,05)$ de forma linear com os níveis de lisina da ração (Figura 1). Do mesmo modo, Fontes et al. $(2000,2005)$ verificaram efeito

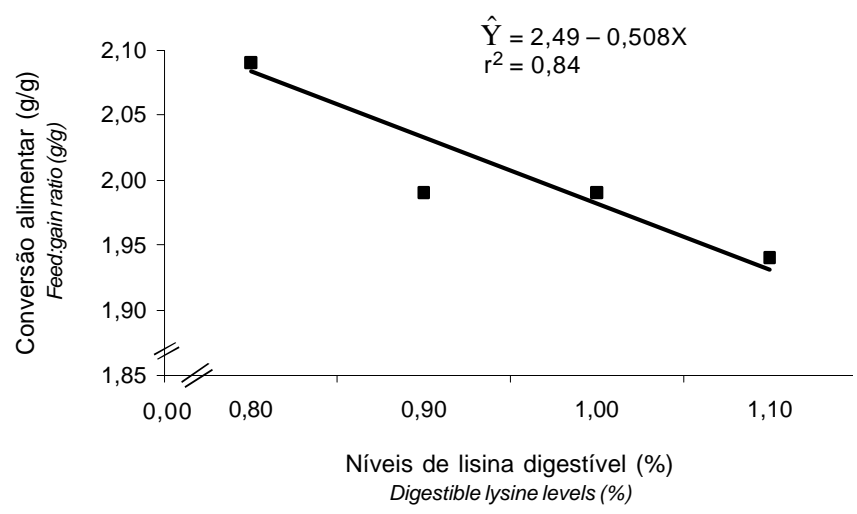

Figura 1 - Efeito dos níveis de lisina digestível da ração sobre a conversão alimentar de suínos machos castrados dos 30 aos $60 \mathrm{~kg}$.

Figure 1 - Effect of dietary lysine levels on feed:gain ratio of barrows from 30 to $60 \mathrm{~kg}$.

linear decrescente dos níveis de lisina da ração sobre a conversão alimentar de leitoas de alto potencial genético na mesma fase de crescimento.

A concentração de uréia no plasma (UP) dos animais não foi influenciada pelos níveis de lisina na ração. Resultados semelhantes foram obtidos por Fontes et al. (2000, 2005) em leitoas de 30 a $60 \mathrm{~kg}$.

Segundo Cameron et al. (2003), a lisina consumida além das necessidades de mantença e de deposição de proteína é catabolisada e o nitrogênio resultante desse catabolismo é excretado como uréia. Assim, a relação uréia plasmática $\times$ lisina na ração deve ser não-linear e deve ocorrer um ponto de inflexão no nível de lisina correspondente à exigência do animal. Neste estudo, não houve ponto de inflexão para a concentração de uréia plasmática dos animais em resposta aos níveis de lisina na ração. Duas hipóteses podem explicar esses resultados da UP: é possível que a exigência de lisina digestível dos animais tenha sido alcançada no último nível de lisina avaliado ou que esteja acima desse nível, conforme 
observado para a CA, não permitindo que ocorresse ponto de inflexão. De fato, o menor valor numérico da UP foi observado no nível de $1,10 \%$ de lisina digestível, parecendo indicar melhor utilização do nitrogênio da dieta à medida que se elevaram os níveis de lisina digestível.

Outra possibilidade é que a UP não tenha sido um parâmetro adequado para a determinação da exigência de lisina para suínos machos castrados dos 30 aos $60 \mathrm{~kg}$, pois, segundo Cameron et al. (2003), o uso da uréia sangüínea na estimativa da exigência de lisina deve ser limitado para animais com peso superior a $70 \mathrm{~kg}$. Da mesma forma, Friesen et al. (1994) concluíram que o teor de uréia no sangue não é um parâmetro adequado para estimar as exigências de lisina de suínos na fase de crescimento.

Segundo Fontes et al. (2005), o número de animais utilizados no estudo e o padrão de consumo de ração pelos animais durante o protocolo de coleta de sangue podem ser causas de variabilidade nos valores de uréia sangüínea, o que pode dificultar a utilização da uréia plasmática como parâmetro preditor da exigência de lisina para suínos de 30 a $60 \mathrm{~kg}$.

Os resultados da composição química e das deposições de proteína e de gordura na carcaça de suínos machos castrados dos 30 aos $60 \mathrm{~kg}$ recebendo diferentes níveis de lisina na ração são apresentados na Tabela 3. De modo similar aos resultados obtidos por Fontes et al. (2000), os níveis de lisina não afetaram as porcentagens de água, proteína e gordura da carcaça dos animais.

Os tratamentos influenciaram de forma linear $(\mathrm{P}<0,05)$ a deposição de proteína (DP) na carcaça (Figura 2), indicando que, quando a energia da ração não é fator limitante, os suínos respondem a aumentos dos níveis de lisina da ração até o ponto de máxima deposição de proteína no corpo, determinado pela genética. Este ponto, segundo De Lange et al. (2001), corresponde ao nível que proporciona máxima eficiência alimentar. Neste estudo, o nível de lisina digestível que resultou nos melhores resultados de deposição de proteína coincidiu com aquele que resultou em melhores resultados de conversão alimentar.

Os resultados das deposições de proteína e gordura na carcaça dos animais (a relação proteína:gordura aumentou de 0,78 para 1,12 entre os níveis de 0,80 e $1,10 \%$ de lisina digestível) podem justificar a melhora na CA dos animais. Segundo Kyriazakis et al. (1994), a deposição de proteína, por agregar maior quantidade de água, é mais eficiente que a de gordura.

O valor de 1,10\% de lisina digestível encontrado neste estudo, correspondente a um consumo de lisina digestível estimado de 21,94 g/dia, para os melhores resultados de CA e DP, foi superior ao preconizado pelo NRC (1998) e por Rostagno et al. (2005), respectivamente, para animais, dos 20 aos $50 \mathrm{~kg}$ e dos 30 aos $50 \mathrm{~kg}$. Por outro lado, foi semelhante ao de $1,09 \%$ de lisina digestível obtido por

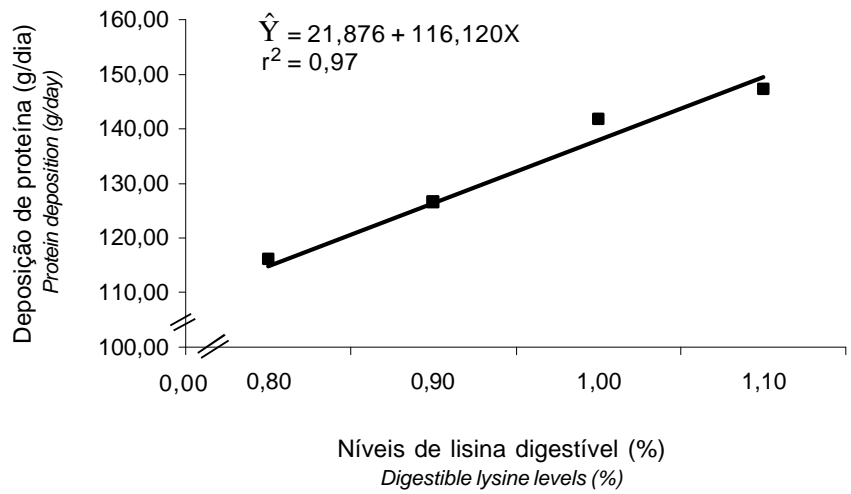

Figura 2 - Efeito dos níveis de lisina digestível da ração sobre a deposição de proteína na carcaça de suínos machos castrados de 30 a $60 \mathrm{~kg}$.

Figure 2 - Effect of dietary lysine levels on daily protein deposition in the carcass of barrows from 30 to $60 \mathrm{~kg}$.

Tabela 3 - Composição química e taxas de deposição de proteína e gordura na carcaça de suínos machos castrados dos 30 aos 60 kg recebendo diferentes níveis de lisina na ração

Table 3 - Chemical composition and protein and fat depositions in the carcass of barrows from 30 to $60 \mathrm{~kg}$ according to the dietary lysine levels

\begin{tabular}{|c|c|c|c|c|c|}
\hline & \multicolumn{4}{|c|}{$\begin{array}{c}\text { Nível de lisina digestível (\%) } \\
\text { Digestible lysine level }\end{array}$} & \multirow[t]{2}{*}{$\mathrm{CV}(\%)$} \\
\hline & 0,80 & 0,90 & 1,00 & 1,10 & \\
\hline \multicolumn{6}{|c|}{ Composição da carcaça (\%) (Carcass composition) } \\
\hline Água (Water) & 59,75 & 61,49 & 60,32 & 60,90 & 2,66 \\
\hline Proteína (Protein) & 17,04 & 17,22 & 17,35 & 17,52 & 4,34 \\
\hline Gordura (Fat) & 16,57 & 14,79 & 16,14 & 14,76 & 13,72 \\
\hline \multicolumn{6}{|c|}{ Deposição na carcaça (g/dia) (Carcass deposition) } \\
\hline Proteína ${ }^{1}$ (Protein) & 116,15 & 126,61 & 141,83 & 147,23 & 14,36 \\
\hline Gordura (Fat) & 148,61 & 134,64 & 139,33 & 131,48 & 23,89 \\
\hline
\end{tabular}

${ }^{1}$ Efeito linear $(P<0,05)$.

1 Effect linear $(P<0.05)$. 
Warnants et al. (2003) para melhor GPD de suínos machos castrados de alto potencial genético dos 30 aos $49 \mathrm{~kg}$.

A deposição de gordura na carcaça dos animais não foi afetada $(\mathrm{P}>0,05)$ pelos níveis de lisina da ração. Este resultado é semelhante ao obtido por Fontes et al. (2000). Entretanto, em valor absoluto, constatou-se decréscimo de $11,5 \%$ na deposição de gordura na carcaça dos animais nos níveis de 0,80 a $1,10 \%$ de lisina na ração.

\section{Conclusões}

O nível de lisina digestível que proporcionou os melhores resultados de conversão alimentar e de deposição de proteína na carcaça em suínos machos castrados de alto potencial genético para deposição de carne magra na carcaça dos 30 aos $60 \mathrm{~kg}$ foi $1,10 \%$, que corresponde a um consumo de lisina digestível de 21,94 g/dia (3,43 g de Lis digestível/Mcal de EM).

\section{Agradecimento}

À AGROCERES NUTRIÇÃO ANIMAL, pela cessão dos animais e das rações experimentais.

\section{Literatura Citada}

CAMERON, N.D.; McCUllough, E.; TROUP, K. et al. Serum urea concentration as a predictor of dietary lysine requirement in selected lines of pigs. Journal of Animal Science, v.81, n.1, p.91-100, 2003.

D'MELLO, J.P.F. Amino acid supplementation of cereal-based diets for non-ruminants. Animal Feed Science and Technology, v.45, n.1, p.1-18, 1993.

DE LANGE, C.F.M.; BIRKETT, S.H.; MOREL, P.C.H. Protein, fat, and bone tissue growth in swine. In: LEWIS, A.J.; SOUTHERN, L.L. (Eds.) Swine nutrition. Florida: CRC Press LLC, 2001. p.65-81.

DONZELE, J.L.; COSTA, P.M.A.; ROSTAGNO, H.S. et al. Efeitos de níveis de energia digestíveis na composição da carcaça de suínos de cinco a quinze quilos. Revista da Sociedade Brasileira de Zootecnia, v.21, n.6, p.1100-1106, 1992.

DONZELE, J.L.; FREITAS, R.T.F.; OLIVEIRA, R.F.M. et al. Níveis de lisina para leitoas de 30 a $60 \mathrm{~kg}$ de peso vivo. Revista da Sociedade Brasileira de Zootecnia, v.24, n.6, p.967-973, 1994.

EDMONDS, M.S.; BAKER, D.H. Amino acid excesses for young pigs: effects of methionine, tryptophan, threonine or leucine. Journal of Animal Science, v.64, n.6, p.1664-1671, 1987.

FONTES, D.O. Lisina para leitoas selecionadas geneticamente para deposição de carne magra na carcaça, dos 15 aos 95 kg. Viçosa, MG: Universidade Federal de Viçosa, 1999. 101 p. Tese (Doutorado em Zootecnia) - Universidade Federal de Viçosa, 1999.
FONTES, D.O.; DONZELE, J.L.; OLIVEIRA, R.F.M. et al. Níveis de lisina para leitoas selecionadas geneticamente para deposição de carne magra, dos 30 aos $60 \mathrm{~kg}$, mantendo constante a relação entre lisina e metionina + cistina, treonina, triptofano, isoleucina e valina. Revista Brasileira de Zootecnia, v.29, n.3, p.776783, 2000.

FONTES, D.O.; DONZELE, J.L.; OLIVEIRA, R.F.M. et al. Níveis de lisina para leitoas selecionadas geneticamente para deposição de carne magra na carcaça, dos 30 aos $60 \mathrm{~kg}$. Revista Brasileira de Zootecnia, v.34, n.1, p.81-89, 2005.

FRIESEN, K.G.; NELSSEN, J.L.; GOODBAND, R.D. et al. Influence of dietary lysine on growth and carcass composition of highlean growth gilts fed from 34 to 72 kilograms. Journal of Animal Science, v.72, n.7, p.1761-1770, 1994.

KESSLER, A.M. Exigências nutricionais para máximo rendimento de carne em suínos. In: SIMPÓSIO SOBRE RENDIMENTO E QUAlidADE DA CARnE SUÍNA, 1998, Concórdia. Anais... Concórdia: 1998. p.18-25.

KYRIAZAKIS, I.; DOTAS, D.; EMMANS, G.C. The effects of breed on the relationship between feed composition and the efficiency of protein utilization in pigs. British Journal of Nutrition, v.71, n.6, p.849-859, 1994.

NATIONAL RESEARCH COUNCIL - NRC. Nutrient requirements of swine. 10.ed. Washington, D.C.: National Academic Press, 1998. $189 \mathrm{p}$.

ROSTAGNO, H.S.; ALBINO, L.F.T.; DONZELE, J.L. et al. Composição de alimentos e exigências nutricionais de aves e suínos: tabelas brasileiras. Viçosa, MG: Universidade Federal de Viçosa, 2000. 141p.

ROSTAGNO, H.S.; ALBINO, L.F.T.; DONZELE, J.L. et al. Tabelas brasileiras para aves e suínos: composição de alimentos e exigências nutricionais. Viçosa, MG: Universidade Federal de Viçosa, 2005. 186p.

SILVA, D.J. Análise de alimentos: métodos químicos e biológicos. Viçosa, MG: Universidade Federal de Viçosa, 1990. 166p.

SOUZA, A.M. Exigências nutricionais de lisina para suínos mestiços, de 15 a $95 \mathrm{~kg}$ de peso. Viçosa, MG: Universidade Federal de Viçosa, 1997. 81p. Dissertação (Mestrado em Zootecnia) - Universidade Federal de Viçosa, 1997.

UNIVERSIDADE FEDERAL DE VIÇOSA - UFV. SAEG - Sistemas de Análises Estatísticas e Genéticas. Versão 8.0. Viçosa, MG: 1997. (CD-ROM).

YEN, H.T.; COLE, D.J.A.; LEWIS, D. Amino acid requirements of growing pigs. 9. The response of pigs from 25 to $55 \mathrm{~kg}$ live weight to dietary ideal protein. Animal Production, v.43, n.3, p. 141-154, 1986.

WARNANTS, N.; Van OECKEL, M.J.; PAEPE, M. Response of growing pigs to different levels of ileal standardized digestible lysine using diets balanced in threonine, methionine and tryptophan. Livestock Production Science, v.82, n.2-3, p.201-209, 2003.
Recebido: 21/09/05 Aprovado: 10/08/06 